\title{
God sykepleie gir færre komplikasjoner ved diabetes type 2
}

Sykepleierens oppgave er å lære pasientene hvordan de kan ivareta god egenomsorg gjennom sunt kosthold, regelmessig aktivitet og riktig bruk av legemidler.

\section{Karin Pleym}

Sykepleier

Endokrinologisk seksjon, Medisinsk poliklinisk senter, Drammen sykehus

\section{Merethe Westberg}

Diabetessykepleier

Endokrinologisk seksjon, Sykehuset i Vestfold

\section{Diabetes \\ Forebygging \\ Helse \\ Informasjon}

\section{Hovedbudskap}

Diabetes type 2 er en kronisk sykdom der egenbehandling er sentralt. God sykepleie innebærer å lære pasientene hva riktig kosthold, fysisk aktivitet og korrekt legemiddelbruk betyr, slik at pasientene selv kan være med på å forebygge senkomplikasjoner. 
Sykepleiere kan møte personer med diabetes type 2 overalt - i skolehelsetjenesten, svangerskapsomsorgen, innenfor psykisk helsevern, på ulike sykehusavdelinger, $\mathrm{i}$ hjemmesykepleien og på sykehjem. Det er viktig at sykepleierne har kunnskaper om diabetes type 2 for å kunne hjelpe pasienter med å oppnå god livskvalitet og forebygge senkomplikasjoner.

Forekomsten av diabetes er $\varnothing$ kende både i Norge og resten av verden. International Diabetes Federation (IDF) anslår at 537 millioner voksne personer nå lever med diabetes på verdensbasis (1). I 2020 ble det estimert at omkring $316000-345000$ personer har diabetes i Norge, og at diabetes type 2 utgjør omtrent 90 prosent av det totale antallet (2).

Genetikk, overvekt og lite fysisk aktivitet er faktorer som gir $\varnothing$ kt disposisjon for diabetes type 2 (3). Det er høyere forekomst av diabetes type 2 blant innvandrere til Norge fra land som Sri Lanka, India og Pakistan (4). Det er vist at gjennomsnittsalderen på diagnosetidspunktet var 8-15 år lavere for kvinner fra minoritetsbefolkningen sammenliknet med den generelle befolkningen i Norge (5).

Diabetes type 2 kan forebygges. Når diabetes type 2 først er oppstått, er det viktig å forebygge senkomplikasjoner som kan følge av langvarig dårlig metabolsk kontroll (3). I arbeidet med å hjelpe pasienter til god egenomsorg og samtidig forebygge senkomplikasjoner spiller sykepleiere en viktig rolle sammen med pasienten, de pårørende og pasientens lege.

\section{Hva er diabetes type 2?}

Diabetes type 2 er en kronisk metabolsk tilstand som utvikler seg langsomt og over tid. Hos personer med diabetes type 2 er kroppens evne til å nyttiggjøre seg av næringsstoffene glukose, fett og proteiner forstyrret på grunn av insulinresistens, insulinmangel eller begge deler (6-8).

Diabetes type 2 er en kronisk og progredierende sykdom. Initialt er tilstanden preget av insulinresistens, som innebærer at hormonet insulin ikke har god nok effekt på cellenivå. I en tidlig fase av sykdomsutviklingen kompenserer kroppen for den manglende insulineffekten ved å øke insulinutskillelsen.

Etter hvert som sykdommen utvikler seg, vil bukspyttkjertelen gradvis miste evnen til å produsere tilstrekkelige mengder insulin til å holde blodsukkernivået normalt, noe som fører til hyperglykemi (6-8). 


\section{Hvordan stilles diagnosen?}

Helsedirektoratet har anført følgende kriterier for å stille diagnosen diabetes type 2: HbAic (glykosylert hemoglobin, også kalt langtidsblodsukker) $\geq 48 \mathrm{mmol} / \mathrm{mol}$ ( $\geq$ 6,5 prosent) eller fastende glukose i plasma $\geq 7,0 \mathrm{mmol} / \mathrm{L}$ og/eller glukose $\geq 11,1$ $\mathrm{mmol} / \mathrm{L}$ to timer etter en glukosebelastningstest (9).

Ved diabetes type 2 ser man i tillegg til hyperglykemi som regel også andre metabolske forstyrrelser som del av det metabolske syndromet (8). IDF definerer metabolsk syndrom som en samling av risikofaktorer for hjerte- og karsykdom, som diabetes, $\varnothing \mathrm{kt}$ fastende blodsukker, abdominal fedme, høyt kolesterol og høyt blodtrykk (10).

\section{Hva er behandlingsmål og kontrollrutiner?}

Nasjonal faglig retningslinje for diabetes gir oppdatert informasjon om valg av behandling av diabetes type 2 (9). Det vektlegges at behandlingen bør ha en individuell tilnærming der pasientens personlige preferanser, eventuelle andre sykdommer og antall forventede leveår tas i betraktning $(6,9,11)$.

HbA1c er en blodprøve som sier noe om gjennomsnittlig glukosekonsentrasjon i plasma de siste to til tre månedene. For de fleste pasientene med diabetes type $2 \mathrm{er}$ behandlingsmålet å oppnå en HbAlc på omkring $53 \mathrm{mmol} / \mathrm{mol}$ (7 prosent). Imidlertid kan det være aktuelt å sette et høyere eller lavere mål for HbAic ut fra pasientens individuelle forutsetninger og andre helserelaterte faktorer (9).

Egenmåling av blodsukkeret kan være et godt verktøy for å lære mer om blodsukkersvingninger, for eksempel i forbindelse med ulike måltider. Blodsukkeret bør da måles systematisk. Et anbefalt system for egenmåling av blodsukkeret kan være fastende, før og to timer etter måltider og eventuelt før sengetid.

Pasienter med diabetes type 2 bør følges opp for helsekontroll hver tredje til sjette måned hos fastlegen. I tillegg bør det utføres en årlig utvidet kontroll - en årskontroll der hovedhensikten er å forebygge senkomplikasjoner ved diabetes type $2(9)$.

\section{Godt kosthold er gunstig}

Gode kostholdsvaner kombinert med regelmessig fysisk aktivitet er grunnleggende $\mathrm{i}$ behandlingen av diabetes type 2. Personer med diabetes anbefales å ha et sunt kosthold som i hovedsak følger de generelle kostanbefalingene utgitt av Helsedirektoratet (9). 
Kostholdsråd til personer med diabetes type 2 bør i tillegg fokusere på å unngå hyperglykemi og bidra til å forebygge hjerte- og karsykdom. For personer med overvekt vil det være gunstig å oppnå en varig vektreduksjon på 5-10 prosent av kroppsvekten $(6,9)$.

\section{«Personer med diabetes type 2 bør begrense inntaket av alle typer tilsatt sukker, inkludert fruktose.»}

Rent konkret bør ernæringsråd til personer med diabetes omfatte et kosthold rikt på grønnsaker og med daglig inntak av bær og frukt i moderate mengder. Det anbefales $\varnothing \mathrm{kt}$ bruk av bønner, erter og linser, fullkornsprodukter, hele korn og kjerner. Personer med diabetes type 2 bør spise fisk, sjømat og fugl i større grad enn rødt kjøtt og bør bruke rene råvarer fremfor farseprodukter (9).

Videre bør kostholdet bestå av magre meieriprodukter, matoljer og myke eller flytende margariner og n $\varnothing$ tter. Personer med diabetes type 2 bør begrense inntaket av alle typer tilsatt sukker, inkludert fruktose. Energifrie søtningsstoffer kan erstatte sukker. Det er også viktig å begrense mengden salt i kosten (9).

\section{Fysisk aktivitet anbefales}

Personer med diabetes type $2 \mathrm{~b} \varnothing \mathrm{r}$ være i regelmessig fysisk aktivitet. Aktiviteten bør ha moderat til høy intensitet og være fordelt på minst tre dager i uken, og det bør ikke være mer enn to påfølgende dager uten fysisk aktivitet. Til sammen er det anbefalt at aktiviteten er av minst 150 minutters varighet per uke (9).

I tillegg til $\varnothing \mathrm{kt}$ fysisk aktivitet er det viktig at personer med diabetes type 2 unngår langvarig stillesittende atferd (11).

\section{Ulike legemidler kan senke blodsukkeret}

Metformin er førstevalget av blodsukkersenkende legemidler for å behandle diabetes type 2 (9). Det er viktig for sykepleiere å være klar over at Metformin bør seponeres ved alvorlig nyresvikt og ved akutte tilstander som gir risiko for nedsatt nyrefunksjon, som for eksempel feber og diaré, og ved undersøkelse der kontrastvæske benyttes.

Dersom man ikke oppnår behandlingsmålene med Metformin i kombinasjon med oppmerksomhet på kosthold og fysisk aktivitet, er det flere andre perorale legemidler som kan benyttes. Nasjonal faglig retningslinje for behandling av diabetes gir god oversikt over de ulike legemidlene (9).

I tillegg til perorale legemidler kan GLP-1-analoger (se faktaboks) gitt som daglig eller ukentlig injeksjon benyttes. 


\section{GLP-1-analoger}

GLP-1-analoger er legemidler som brukes til å behandle diabetes type 2. De senker blodsukkeret ved å stimulere til økt insulinutskillelse fra bukspyttkjertelen.

Kilde: Store medisinske leksikon

\section{Blodsukkersendende behandling ved diabetes type 2}

Se Helsedirektoratets flytskjema for behandling av diabetes type 2 .

Kilde: Helsedirektoratet

\section{Når bør pasienten ta insulin?}

Dersom man ikke kommer i mål med kombinasjoner av ulike perorale legemidler og/eller GLP-1-analoger, bør pasienten begynne med insulin (6, 9, 11). Mange pasienter kan kvie seg for å starte med insulin, og det er derfor viktig at helsepersonell tilbyr god opplæring og støtte til pasienter som skal starte med insulinbehandling (12).

Pasienter som skal starte med insulin, trenger opplæring i riktig injeksjonsteknikk for å unngå lipodystrofi, det vil si groper, infiltrater eller fettputer. Gjentatte insulininjeksjoner på samme sted kan føre til lipodystrofi, som igjen kan medføre uforutsigbar oppsuging av insulin fra underhudsfettet til blodbanen med dertil svingende blodsukker.

\section{«Pasienter som skal starte med insulin, trenger opplæring i riktig injeksjonsteknikk.»}

For pasienter med diabetes type 2 som ikke selv kan sette insulin, er det viktig at sykepleietjenesten har gode rutiner for å variere innstikksstedet. Viktige momenter i administrasjonen av insulin er at insulin skal injiseres i underhudsfettet, ikke i muskler eller blodårer. Hurtigvirkende insulin injiseres som hovedregel i mageregionen, og langtidsvirkende insulin injiseres som hovedregel i låret (13).

Like viktig som å behandle høyt blodsukker er god behandling av de enkelte faktorene i det metabolske syndromet, herunder overvekt, lipider og blodtrykk (6, 9, 11). Sykepleiere bør til enhver tid holde seg oppdatert på virkning og bivirkning av de ulike preparatene som brukes til å behandle diabetes type 2 . 


\section{Sårbare eldre må ha tilpasset behandling}

Forekomsten av diabetes type 2 stiger med $\varnothing$ kende alder. Eldre pasienter med diabetes type 2 er en heterogen gruppe med ulik grad av både kognitiv og fysisk helse. De generelle behandlingsmålene er derfor ikke nødvendigvis tilpasset livssituasjonen til den enkelte eldre.

I møte med sårbare eldre bør behandlingsmålene, både for blodsukker, blodtrykk og lipider, vurderes og individualiseres. Hos eldre pasienter med diabetes type 2 bør behandlingsmålet rettes mot å forbedre livskvaliteten, bevare fysisk funksjon og unngå bivirkninger av behandlingen, spesielt hypoglykemi (14).

Sulfonylureapreparater (SU) stimulerer frisetting av insulin fra bukspyttkjertelen og kan dermed potensielt gi hypoglykemi på samme måte som behandling med insulin. SU har langsom utskillelse, og preparatet frarådes derfor brukt på eldre grunnet fare for langvarig og alvorlig hypoglykemi (15).

Skrøpelige eldre med diabetes har høyere risiko for flere geriatriske utfordringer som kognitiv svikt, depresjon, urininkontinens, $\varnothing \mathrm{kt}$ falltendens og kroniske smerter (11).

Formålet med diabetesbehandlingen i denne pasientgruppen $b \varnothing r$ først og fremst dreie seg om å unngå plager relatert til høyt eller lavt blodsukker i hverdagen. Lavt blodsukker kan for eksempel føre til forvirring eller fall med skader. For høyt blodsukker kan på den andre siden føre til hyppig vannlating og fare for urinveisinfeksjoner.

\section{«Det er viktig at sårbare eldre får i seg sunn, variert og næringsrik kost.»}

Selv om overvekt også kan være et problem i den eldste delen av befolkningen, lider mange skrøpelige eldre av underernæring og mangel på mikronæringsstoffer (16).

Det er viktig at sårbare eldre får i seg sunn, variert og næringsrik kost. Maten som tilbys eldre pasienter med diabetes type 2 , bør derfor balanseres mellom behovet for næring, blodsukkerkontroll og livskvalitet snarere enn å innføre unødvendig strenge restriksjoner i kostholdet. Regelmessig mosjon for de som trygt kan delta i slike aktiviteter, er anbefalt også for eldre pasienter med diabetes type 2 (11). 


\section{Senkomplikasjoner kan forebygges}

Diabetessenkomplikasjoner deles inn i mikro- og makrovaskulære komplikasjoner. De mikrovaskulære komplikasjonene er skader som oppstår i små blodkar. Typiske organer som rammes, er øyne - reinopati, nyrer - nefropati og perifere nerver nevropati (8).

Makrovaskulære senkomplikasjoner er sykdom eller skade som oppstår i de store blodkarene i kroppen. Eksempler på makrovaskulære komplikasjoner ved diabetes kan være hjerneslag og hjerteinfarkt (8).

De viktigste kardiovaskulære risikofaktorene for pasienter med diabetes type $2 \mathrm{er}$ trolig arv, blodtrykk, røyking og dyslipidemi, som er betegnelsen på et misforhold mellom serumnivåene av total- og HDL-kolesterolet og triglyserider (8). A motivere og bistå til røykeslutt er dermed en viktig oppgave både for sykepleiere og annet helsepersonell som har omsorg for pasienter med diabetes type 2 (9).

Nevropati kan oppstå både i det autonome og sensoriske nervesystemet. Vanligst er perifer nevropati, som kan gi smerter, følelsesløshet, tørr hud, tap av behåring og feilstillinger i føttene. Med lite følsomhet i føttene er man mer utsatt for trykkskader som kan gi diabetesfotsår. I verste fall kan det føre til amputasjon (9).

\section{Slik kan fotsår forebygges}

Gode sko, rene og tørre sokker og daglig kontroll av føttene er viktige tiltak for å forebygge diabetesfotsår. Regelmessig stell av føttene hos fotterapeut anbefales for alle som ikke klarer å stelle føttene godt nok selv. Dersom pasienten med diabetes type 2 ikke kan utføre egenkontroll av føttene, må en sykepleier sørge for at vedkommende får hjelp til dette.

Kontroll av føtter innebærer observasjon av eventuelle sprekker i huden, som gir en inngangsport for bakterier, og tørr hud, som da bør smøres regelmessig. Føttene inspiseres for å se etter områder med hard og fortykket hud.

Hard hud bør vurderes fjernet hos fotterapeut fordi det gir $\varnothing k t$ trykk på det underliggende vevet, noe som kan føre til sårdannelse. Dersom pasienten har fotdeformiteter, bør legen henvise til ortopediingeniør for å få fotsenger og/eller tilpasset fottøy (9).

Det er viktig at pasienten benytter fotsenger også ved bevegelse innendørs. Etablert fotsopp og neglesopp bør behandles (9). Ved regelmessig inspeksjon av føttene kan nyoppståtte sår oppdages raskt og adekvat sårbehandling iverksettes. 
Pasienter med diabetes kan oppleve redusert tannhelse i form av både karies og periodontitt. Derfor er det viktig at sykepleiere hjelper pasienten med å oppnå god munnhygiene når pasienten selv ikke greier det (17).

\section{God kommunikasjon kan gi mestring}

Pasienter med diabetes type 2 har behov for både kunnskaper, ferdigheter og motivasjon for å kunne ivareta god egenomsorg. Derfor er det essensielt med tilstrekkelig og riktig helseinformasjon kombinert med sosial støtte for at disse pasientene skal lykkes med å oppnå anbefalte behandlingsmål og oppleve mestring i hverdagen (18).

For mange kan det å få diagnosen diabetes type 2 oppleves som både traumatisk og stigmatiserende. Diabetes type 2 er karakterisert som en livsstilssykdom, og det kan føre til at enkelte pasienter føler både skyld og skam relatert til diagnosen. Det er viktig at sykepleiere tar hensyn til dette aspektet i sin tilnærming til pasienter med diabetes type 2.

\section{«For mange kan det å få diagnosen diabetes type 2 oppleves som både traumatisk og stigmatiserende.»}

Sykepleiere bør s $\varnothing \mathrm{ke}$ å bidra til at pasienter med diabetes type 2 finner gode mestringsstrategier. Nasjonal faglig retningslinje for diabetes (9) har følgende anbefalinger til spørsmål som kan stilles i samhandling med pasienter med diabetes type 2: Hvordan har det gått siden sist? Hvordan synes du det er å ha diabetes? Hva er det som tynger, og hva er det som gleder deg? Hva mestrer du godt, og hva opplever du som vanskelig? (9)

På Diabetesforbundets nettsider finnes e-læringskurs for personer med diabetes type 2. Disse kursene handler om å gi kunnskap om diabetes, men også om hvordan det føles å leve med diagnosen diabetes type 2 (19).

\section{Pasientene bør henvises til lærings- og mestringskurs}

Pasienter med nyoppdaget diabetes type 2 bør henvises til lærings- og mestringskurs i spesialisthelsetjenesten. Å leve med diabetes type 2 griper inn i hverdagslivet og den sosiale konteksten som pasienten lever i. Derfor kan pårørende med fordel delta på lærings- og mestringskurs sammen med pasienten.

De fleste kommunene har etablert frisklivssentraler der personer med ulike diagnoser kan få hjelp til å komme i fysisk aktivitet, få undervisning om kosthold og hjelp med tobakksavvenning. 
Pasienter og pårørende er ulikt rustet til å motta og anvende informasjon og undervisning om helserelaterte temaer. I møte med pasienter med diabetes type 2 er det viktig at helsepersonell tar hensyn til pasientens helseinformasjonsforståelse, også kalt health literacy (HL).

For pasienter med diabetes, der behandlingen for det meste består av egenbehandling, kan lavt nivå av HL være assosiert med dårligere blodsukkerkontroll (20). Helseinformasjonsforståelse er en faktor som sykepleiere bør vurdere når de planlegger og gir informasjon og opplæring til pasienter med diabetes type 2 .

\section{Konklusjon}

Diabetes type 2 er en kompleks sykdom, der behandlingen i stor grad består av egenbehandling. God sykepleie til pasienter med diabetes type 2 innebærer opplæring i god egenomsorg. Helseinformasjonsforståelse må vektlegges i opplæringen av pasienter og pårørende.

Diabetes type 2 kan forebygges gjennom $\varnothing \mathrm{kt}$ oppmerksomhet på helsefremmende levevaner. Når diabetes type 2 først er oppstått, kan senkomplikasjoner som følge av langvarig dårlig regulert blodsukker forebygges gjennom god individualisert behandling og regelmessige helsekontroller.

Sykepleierens oppgave i møte med pasienter med diabetes type 2 er å hjelpe dem med å få til en god egenomsorg og bistå når pasientene selv ikke kan ivareta egenomsorgen på en tilfredsstillende måte.

\section{Referanser}

1. IDF Diabetes Atlas. Diabetes around the world in 2021. Brussel: International Diabetes Federation; 2021. Tilgjengelig fra: https://diabetesatlas.org/ (nedlastet 22.11.2021).

2. Stene LC, Ruiz PL-D, Åsvold BO, Bjark $\varnothing$ VV, Sørgjerd EP, Njølstad I, et al. Hvor mange har diabetes i Norge i 2020? Tidsskr Den Nor Legeforening. 12.11.2020. DOI: $10.4045 /$ tidsskr.20.0849

3. Tuomilehto J, Lindström J, Eriksson JG, Valle TT, Hämäläinen H, IlanneParikka P, et al. Prevention of type 2 diabetes mellitus by changes in lifestyle among subjects with impaired glucose tolerance. N Engl J Med. 2001;344(18):1343-50.

4. Folkehelseinstituttet. Helse i innvandrerbefolkningen. Oslo:

Folkehelseinstituttet; 2017. Tilgjengelig fra:

https://www.fhi.no/nettpub/hin/grupper/helse-i-innvandrerbefolkningen/ (nedlastet 
5. Tran AT, Diep LM, Cooper JG, Claudi T, Straand J, Birkeland K, et al. Quality of care for patients with type 2 diabetes in general practice according to patients' ethnic background: a cross-sectional study from Oslo, Norway. BMC Health Serv Res. 2010;10(1):145.

6. National Institute for Health and Care Excellence (NICE). Type 2 diabetes in adults: management. London, Manchester: NICE: 2020. Tilgjengelig fra: https://www.nice.org.uk/guidance/ng28/chapter/Introduction (nedlastet 14.11.2021).

7. Dunning T, Sinclair AJ. Care of people with diabetes: a manual for healthcare practice. 5. utg. Hoboken, New Jersey: John Wiley and Sons; 2020.

8. Sagen JV. Sykdomslære. I: Skafjeld A, Graue M, red. Diabetes. Forebygging, oppfølging, behandling. Oslo: Akribe; 2013.

9. Helsedirektoratet. Diabetes. Nasjonal faglig retningslinje. Oslo: Helsedirektoratet; 2020. Tilgjengelig fra: https://www.helsedirektoratet.no/retningslinjer/diabetes (nedlastet 21.01.2021).

10. International Diabetes Federation (IDF). Consensus statements. Brussel: IDF; 2020. Tilgjengelig fra: https://www.idf.org/e-library/consensus-statements/60idfconsensus-worldwide-definitionof-the-metabolic-syndrome.html (nedlastet 22.11.2O21).

11. American Diabetes Association. Standards of medical care in diabetes -2020 . Abridged for primary care providers. Clin Diabetes. 2020;38(1):10-38.

DOI: $\underline{10.2337 / \mathrm{cd} 20 \text {-aso1 }}$

12. Hordvik K, Haugstvedt A, Bendixen BE. Hvorfor vegrer pasienter med type 2diabetes seg mot insulinbehandling? Sykepleien. 2019;107(79197):e-79197. DOI: 10.4220/Sykepleiens.2019.79197

13. Helsebiblioteket. Diabetes type 2 og insulinbehandling. Helsebiblioteket; 2021. Tilgjengelig fra: https://www.helsebiblioteket.no/pasientinformasjon/allebrosjyrer/diabetes-type-2-bor-jeg-ta-insulin (nedlastet 12.12.2021).

14. Gómez-Huelgas R, Peralta FG, Rodríguez ML, Formiga F, Domingo MP, Bravo JJM, et al. Treatment of type 2 diabetes mellitus in elderly patients. Rev Clin Esp. 2018;218(2):74-88. 
15. Norsk legemiddelhåndbok. Kronisk nyresykdom. Oslo: Norsk

legemiddelhåndbok; 2020. Tilgjengelig fra:

https://www.legemiddelhandboka.no/T13.4.3/Kronisk_nyresvikt (nedlastet 31.10.2021).

16. Kezerle L, Shalev L, Barski L. Treating the elderly diabetic patient: special considerations. Diabetes Metab Syndr Obes. 2014;7:391-400.

17. Jansson H, Lindholm E, Lindh C, Groop L, Bratthall G. Type 2 diabetes and risk for periodontal disease: a role for dental health awareness. J Clin Periodontol. 2006;33(6):408-14.

18. Oftedal B. Perceived support from family and friends among adults with type 2 diabetes. Eur Diabetes Nurs. 2014;11(2):43-8.

19. Diabetesforbundet. Kurs på nett. Oslo: Diabetesforbundet; 2021 Tilgjengelig fra: https://www.diabetes.no/tilbud-til-deg/kurs-pa-nett/ (nedlastet 12.12.2021).

20. Schillinger D, Grumbach K, Piette J, Wang F, Osmond D, Daher C, et al. Association of health literacy with diabetes outcomes. JAMA. 2002;288(4):475-82. 